\title{
GHOST MOTH IN SPIDER WEB AT THE PAS, MANITOBA
}

WALTER KRIVDA, Box 864, The Pas, Manitoba. R9A 1K8

We are accustomed to see small moths, flies and wasps caught in a spider's web but it was a surprise to find a moth as large and heavy as a ghost moth in a web. There are six species of ghost moths in Manitoba. This is the large Sthenopis quadriguttatus. I am indebted for the specimen of the ghost moth (now in my collection) and for this observation to Philip Reader of Reader's Lake.

The moth was found in a web with its attendant spider, on a waist high shrub, in a gravel pit about $12 \mathrm{mi}$. north of The Pas. The area borders on a Sphagnum bog. It is possible that this ghost moth is one of three species which inhabit acid bogs. It is said the larva feeds at the roots of trees and alders underground for several years before pupating and emerging as an adult. Two species of alder occur here.

The spider held the moth in its web. When the moth was removed from the web, it fell to the ground, so that moth and spider were briefly separated. Very quickly the spider found its prey again and pounced on it. The left hind wing is mostly missing. The remaining three are in reasonable condition. The spider silk windings were around the whole moth. There are two small puncture holes in the abdomen just below the thorax, made by the fang bites of the spider.

The moth was moribund when found by Reader. The action of the poison must be rapid as the entire specimen still looks very fresh considering its ordeal. The abdomen is rather black in the dry, preserved specimen. This is a strange colour for a dry specimen in this species. Over 100 specimens in the writer's collection fail to show this, most remain flesh coloured. Even a specimen taken in 1949 has kept its colour well. The discoloration may be due to the spider venom. The spider was unfortunately lost in the grass, so that the species responsible for the attack is unknown.

\section{POLYPHEMUS AT LA RONGE}

This picture was taken at La Ronge, Saskatchewan in July 1982 . The timber that it is sitting upon is $4^{\prime \prime}$ wide, to give an idea of its size. - Myron Barton, R.R. \#5, Site 16, Box 51, Prince Albert, Saskatchewan. S6V 5R3

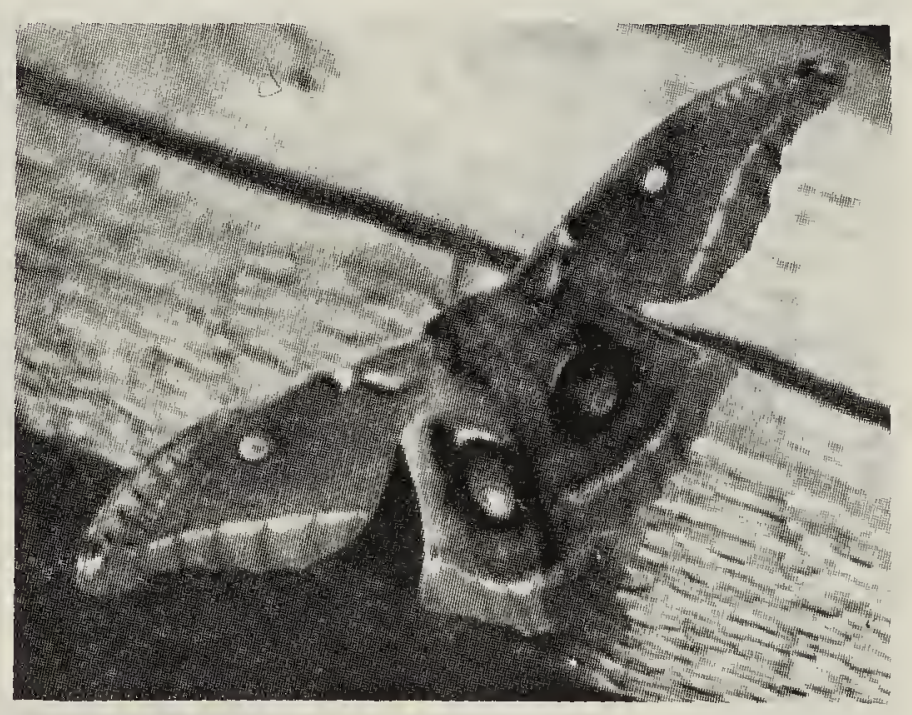

EDITOR'S NOTE: The moth is a Polyphemus Silk Moth (Antheraea polyphemus). It has been collected previously at La Ronge, which is the farthest north that it has so far been recorded in central Saskatchewan. - R.R. Hooper 